\title{
The knowledge and attitude of primary school teachers in Sri Lanka towards childhood attention deficit hyperactivity disorder
}

\author{
M D A Rodrigo', D Perera'1, V P Eranga'1, S S Williams'1, K A L A Kuruppuarachchi ${ }^{1}$ \\ (Index words: attention deficit hyperactivity disorder, teachers' knowledge and attitude, Sri Lanka)
}

\begin{abstract}
Objective To assess the knowledge and attitudes towards attention deficit hyperactivity disorder (ADHD) among primary school teachers in the Gampaha District.

Methods A descriptive cross sectional study was conducted in randomly selected schools of Gampaha district using a stratified sampling method. The knowledge and attitudes on ADHD were assessed by a self-administered questionnaire distributed among all the consenting primary school teachers in the selected schools.
\end{abstract}

Results Total of 202 completed questionnaires of 210 distributed were returned. The majority showed good understanding about ill effects of ADHD, teachers' role in management and counterproductive effects of punishment. Three-fourths had a positive attitude towards behavioural therapy. However, only a minority had adequate knowledge about the presentation of ADHD and its treatment with medication. More than $80 \%$ of teachers believed that the parents were to be blamed for the child's ADHD. The majority of participating teachers also believed that behavioural disturbances caused by ADHD children were deliberate and malicious. Teachers who had training in child psychology recorded a significantly higher knowledge and had a more favourable attitude.

Conclusions The knowledge of ADHD and its treatment among primary school teachers needs to be improved. Particular focus should be on improving attitudes and disseminating the message that timely interventions can make a difference in the educational and social development of the child.

Ceylon Medical Journal 2011; 56: 51-54

\section{Introduction}

Attention deficit hyperactivity disorder (ADHD) is the most commonly studied and diagnosed psychiatric disorder in children, affecting 3 to $5 \%$ of children globally [1]. Childhood ADHD can be a disabling illness. If severe forms are left untreated it interferes significantly with the child's education, interpersonal relationships and ability to maintain a generally positive sense of self [2]. Ill effects of the illness go beyond the child, having detrimental effect on family relationships. ADHD is associated with significant psychiatric co-morbidity, $50-60 \%$ of affected children meeting criteria for at least one additional psychiatric disorder [3]. Thirty to $50 \%$ of those diagnosed with ADHD in childhood continue to have symptoms into adulthood $[4,5]$.

With timely treatment many children with ADHD achieve their potential in school and as individuals [6]. Therefore identifying affected children early and referring them for treatment is of great importance. Many a time the behaviours associated with ADHD are first observed in the classroom setting and a teacher is the first person to raise concerns about the child [7]. Nearly $40 \%$ of medical referrals regarding ADHD are initiated by the teachers [8]. Teachers are invaluable sources of information in making the diagnosis of ADHD and $77 \%$ of physicians attempted to obtain a written report from the schools of children who had been referred for ADHD [9].

The most effective therapeutic approach for childhood ADHD is multimodal treatment which consists of multiple elements including stimulant medication, parental training, educational programmes, behavioural techniques at school and home $[6,10]$. Teachers play a key role in many aspects of ADHD treatment planning and implementation. Insufficient knowledge and negative attitudes towards ADHD and its treatment among teachers result in lack or improper implementation of management recommendations leading to treatment failure [11, 12, 13]. Teachers may take harsh and unjust punitive actions against the affected child who is unable to complete school tasks and has apparent disruptive behaviour in the classroom. This could result in counterproductive outcomes and negative consequences [14].

Considering the importance of knowledge and attitude towards ADHD among primary school teachers, it is surprising that relatively little research has been undertaken in this area. The knowledge and attitudes towards ADHD among Sri Lankan school teachers remains largely unknown. This study investigated the knowledge and attitudes towards ADHD and their determinants among elementary school teachers in the Gampaha District.

\footnotetext{
${ }^{1}$ Department of Psychiatry, Faculty of Medicine, University of Kelaniya, Sri Lanka.

Correspondence: MDAR, e-mail: <asirir2000@yahoo.com>. Received 29 November 2010 and accepted 22 January 2011. Competing interests: none declared
} 


\section{Methods}

The study was approved by the Ethical Review Committee of the Faculty of Medicine, University of Kelaniya, Sri Lanka and permission was obtained from respective school authorities.

This cross sectional descriptive study investigated primary school teachers from randomly selected government and semi-government schools in the Gampaha district, Sri Lanka. Schools were selected by stratified sampling method using a list of schools in the Gampaha district. Private schools were excluded due to the difficulty in obtaining permission. All consenting teachers of year 1 to 5 classes of the selected schools were included in the study.

The collection of data was carried out using a 2-paged self-administered questionnaire. The questionnaire was designed after carefully studying the scales used in previous similar studies including Knowledge of Attention Deficit Disorders Scale(KADDS) [14,16-18]. The questions were modified to suit the Sri Lankan context following discussion with two psychiatrists, an educational psychologist and a teacher trainer. The initial questionnaire was prepared in English and translated to Sinhalese and Tamil by bilingual clinicians. Questionnaires were made available in all three languages.

In the questionnaire, teachers were provided with 12 statements to measure knowledge and perceptions of various aspects of ADHD such as diagnosis, aetiology, treatment and prognosis. The respondents were asked to indicate if they agreed, disagreed or did not know using the 5-point Likert-type scale. The questionnaire was pilot- tested on 10 teachers from a local school who volunteered to participate in the pilot study. The pilot test confirmed that the survey took less than 15 minutes to complete. Minor changes in wording were made in response to written and verbal feedback from the pilot group.

A covering letter explaining the purpose of the study, ensuring anonymity and confidentiality was attached with each questionnaire. Selected schools were visited by researchers at a pre-arranged time. Questionnaires were distributed among the participating teachers and collected soon after they were completed. Statistical analysis was performed using Statistical Package for Social Sciences (SPSS) version 12 for Windows.

\section{Results}

Eight schools in the Gamapha district were randomly selected; 7 government schools and a semi-government school. Total of 206 questionnaires were returned (98\%) while $202(96 \%)$ were duly filled. One hundred and seventy teachers $(84.1 \%)$ were employed at government schools and $32(15.8 \%)$ at the semi-government school. The mean age of the participants was 44 years (standard deviation $(\mathrm{SD})=9.1)$ and they reported an average of $15(\mathrm{SD}=7.7)$ years of teaching experience. About half (51.5\%) of participants, had received training in child psychology.

The percentage of teachers who agreed with statements on the 5-point Likert-type scale is illustrated in the Table. For the sake of clarity, 'strongly agree' and 'agree' responses in the questionnaire were combined as a single category of 'agree'.

Table. Teachers' knowledge and views on ADHD

\begin{tabular}{lc}
\hline Item & \% agreed \\
\hline Hyperactivity, inattentiveness and impulsivity are symptoms of ADHD & 47.4 \\
ADHD may express only at school & 42.6 \\
Above all ADHD is a result of bad upbringing & 80.1 \\
ADHD can be treated with medicines & 19.8 \\
ADHD can be treated with behavioural therapy & 74.2 \\
A child with ADHD is likely to have psychiatric illnesses in the future & 62.4 \\
Ifnot controlled, ADHD can result in academic failures & 71.3 \\
Punishment will improve behaviour of a child with ADHD & 16.8 \\
Children with ADHD are malicious & 56.5 \\
Teachers play an important role in detecting and treating children with ADHD & 82.2 \\
Additional assistance at school is beneficial for children with ADHD & 70.3 \\
A child with ADHD has a lower IQ than his peers & 41.5
\end{tabular}


The teachers' knowledge about symptoms and presentation of ADHD were below 50\%. There was a good understanding about ill effects of ADHD, teachers' role in management and counterproductive effects of punishment. While teachers' attitude towards behavioural therapy was positive, they had limited knowledge about its treatment with medication. More than $80 \%$ of teachers recorded that ADHD was a result of poor parental upbringing. Majority (56.5\%) of participating teachers, were of the opinion that behavioural disturbances caused by ADHD children were deliberate and malicious. Teachers who had training in child psychology had significantly higher scores on knowledge and had a more favourable attitude $(\mathrm{p}=0.05)$. Other studied demographic variables including the teachers' period of service, type of school, grade taught and training institution had no significant correlation with the knowledge score.

\section{Discussion}

Exceptionally high return rate of questionnaires may have been due to researchers collecting questionnaires soon after they were filled and high level of enthusiasm and patronage of the school authorities. The knowledge and positive attitudes towards ADHD recorded in this study is lower than the studies conducted in Western countries, but comparable to the studies conducted in low and middle income countries $[8,15]$. However, direct comparisons are difficult due to differences in methodology of studies and participants.

The limited knowledge of symptoms and presentation of ADHD among teachers have significant impact on their effectiveness as key players in the initial screening and diagnosis. However, it should be noted that a significant proportion of teachers, $31 \%$ and $34 \%$ for the first two questions, were aware that their knowledge was poor by indicating they did not know the answers. Similarly, poor perceptions on effectiveness of ADHD medication may have an effect on referring affected children to specialists for treatment and long term adherence to ADHD medication. In contrast, a vast majority responded that behavioural therapy was beneficial although detailed knowledge of behavioural therapy was not assessed. While only $5 \%$ of teachers viewed punishment as a productive way of dealing with ADHD children, the majority believed children with ADHD are malicious. Apparent dissonance of those two views may be partly explained by underreporting of views in favour of punishment due to social desirability factor. The widely held belief of ADHD being a result of poor parental upbringing may impede fostering relationship between parents and teachers which is vital for successful multimodal therapy of ADHD.

A person with deficient knowledge may be cautious and seek information, but a person who holds an incorrect view may not seek additional information and may recommend inappropriate advice. Many teachers in this study not only understood that their knowledge was poor, they also identified responsibility in detecting, treating ADHD and providing extra educational assistance to those children. This is an encouraging sign for the future and emphasises the importance of providing teachers with preservice or in-service training on common childhood psychological problems including ADHD. This recommendation is supported by the fact that teachers who had training in child psychology exhibited better knowledge and more favourable attitudes.

A significant limitation of this study is the possibility of sample bias. The respondents were only from the Gampaha district, which may not be representative of the rest of the country.

\section{References}

1. Nair J, Ehimare U, Beitman BD, Nair SS, Lavin A. Clinical review: evidence-based diagnosis and treatment of ADHD in children. Missouri Medicine 2006; 103: 617-21.

2. Molina BS, Hinshaw SP, Swanson JM. The MTA at 8 years: prospective follow up of children treated for combined-type ADHD in a multisite study. Journal of the American Academy of Child and Adolescent Psychiatry 2009; 48: 484-500.

3. Jensen PS, Hinshaw SP, Kraemer HC, et al. ADHD co morbidity findings from the MTA study: comparing comorbid subgroups. Journal of the American Academy of Child and Adolescent Psychiatry 2001; 40: 147-58.

4. Van Cleave J, Leslie LK. Approaching ADHD as a chronic condition: implications for long term adherence. Journal of Psychosocial Nursing and Mental Health Services 2008; 46: $28-37$

5. Elia J, Ambrosini PJ, Rapoport JL. Treatment of attentiondeficit-hyperactivity disorder. New England Journal of Medicine 1999; 340: 780-8.

6. Richters JE, Arnold LE, Jensen PS, et al. NIMH collaborative multisite multimodal treatment study of children with ADHD. Journal of the American Academy of Child and Adolescent Psychiatry 1995; 34: 987-1000.

7. Weber KS, Frankenberger W, Heilman K. The effects of Ritalin on the academic achievement of children diagnosed with attention-deficit hyperactivity disorder. Developmental Disabilities Bulletin 1992; 20: 49-68.

8. Snider VE, Frankenberger W, Aspenson M. The relationship between learning disabilities and attention deficit hyperactivity disorder: a national survey. Developmental Disabilities Bulletin 2000; 28: 18-38.

9. Kwasman A, Tinsley BJ, Lepper HS. Paediatricians' knowledge and attitudes concerning diagnosis and treatment of attention deficit and hyperactivity disorder. Archives of Paediatric Adolescent Medicine 1995; 149: 1211-6.

10. The MTA Cooperative Group. A 14-month randomized clinical trial of treatment strategies for attention-deficit hyperactivity disorder (ADHD). Archives of General Psychiatry 1999; 56: 1073-86.

11. Eckert TL, Hintze JM. Behavioural conceptions and applications of acceptability: issues related to service delivery 


\section{Papers}

and research methodology. School Psychology Quarterly 2000; 15: 123-48.

12. Wilson LJ, Jennings JK. Parents' acceptability of alternative treatments for attention-deficit hyperactivity disorder. Journal of Attention Disorders 1996; 1: 114-21.

13. Wickstrom KE, Jones KM, LaFleur LH, Witt JC. An analysis of treatment integrity in school-based behavioural consultation. School Psychology Quarterly 1998; 13: 141-54.

14. Snider VE, Busch T, Arrowood L. Teacher knowledge of stimulant medication and ADHD. Remedial and Special Education 2003; 24: 46-56.

15. Ghanizadeh A, Bahredar M, Moeini S. Knowledge and attitudes towards attention deficit hyperactivity disorder among elementary school teachers. Patient Education and Counselling 2006; 63: 84-8.

16. Doherty SL, Frankenberger W, Fuhrer R, Snider V. Children's self-reported effects of stimulant medication. International Journal of Disability, Development and Education 2000; 47: 39-54.

17. Reid R, Vasa SF, Maag JW, Wright G. An analysis of teachers' perceptions of attention deficit disorder. The Journal of Research and Development in Education 1994; 27: 193-202.

18. Runnheim VA, Frankenberger W, Hazelkorn M. Medicating students with emotional and behavioural disorders and ADHD. Behavioural Disorders 1996; 21: 306-14. 